\title{
El viaje mítico en Ora maritima de Rafael Alberti
}

\author{
José María BALCELLS \\ Universidad de León
}

Con precedencia a nuestra breve aproximación al tema del viaje mitológico en la poesía de Rafael Alberti, me parece procedente anticipar que vamos a centrarnos en un libro concreto del poeta, el titulado Ora marítima, aparecido 1953 junto a Baladas y canciones del Paraná ${ }^{1}$. Empero, antes de adentrarnos en dicho conjunto será conveniente referirse de manera sucinta a la presencia de la mitología, de la mitología clásica para ser más exactos, en la obra poética albertiana. Un estudio ad hoc, realizado por Concepción Argente del Castillo, va a servirnos de guía para seguir, a grandes trazos, la evolución de esta veta temática en la poesía del gaditano.

La estudiosa antecitada señala que el mito clásico no aparece en los versos de Rafael Alberti hasta el conjunto Cal y canto, publicado en 1929 y escrito entre 1926 y 1927. Ahí encontramos, en efecto, la composición "Venus en el ascensor (cielos: 1, 2, 3, 4, 5, 6, 7)", en la que, además de esta diosa, asoman al texto Eros, Apolo, Orfeo, Ceres, Baco, así como diversos protagonistas de leyendas míticas (Ganimedes, Narciso). La óptica con que se enfoca la mitología en este poema es lúdica, y responde al espíritu desmitificador vanguardista del que participó el poeta por entonces. Reparemos también en el título, en el que se juntan ya mito y viaje, un viaje que tiene la particularidad de constituirse en un trayecto ascensional hasta el séptimo cielo, y dentro de un ingenio mecánico moderno. A vueltas de esta composición, Argente del Castillo concluye que "si, por una parte, asistimos a la destrucción del mito, también podemos captar, por otra, su revitalización al buscar en el propio presente esta encarnación". (Argente del Casti1lo, 1985,33).

Dejando atrás el poema recién citado, se señala en el trabajo de referencia que se suceden casi tres lustros, en la singladura poética de Rafael Alberti, en los que se produce una progresiva mitologización. Se trata del período que va desde Entre el clavel y la espada, obra que vio la luz en 1941, hasta Ora marítima, libro que, como antes se con-

${ }^{1}$ He aquí la referencia de la primera edición: Ora marítima. Baladas y canciones del Paraná. Buenos Aires: "Colección Poetas de España y América", Losada, 1953, 167pp. En el libro se reproduce una pintura de Rafael Alberti inspirada en Menesteo, y un dibujo de Juan Battle Planes. 
signó, saldría en 1953. En este marco cronológico se gestaron creaciones de gran importancia en la trayectoria literaria del autor: Pleamar (1944), A la pintura (1945) y Retornos de lo vivo lejano (1952).

En Entre el clavel y la espada es Venus nuevamente la deidad que inspira al gaditano, pero aquí bajo pretexto erótico, como se preanuncia en el título del poema, "Diálogo entre Venus y Príapo". En Pleamar, el universo mítico heleno está representado por Arión y por Tirteo, mientras en A la pintura son frecuentes las menciones a dioses y a diosas del Olimpo, no sin acaso el poeta dedica los versos de muchos de los poemas a pintores que plasmaron en sus lienzos asuntos mitológicos. En Retornos de lo vivo lejano reaparece de manera explícita la mitología en los endecasílabos de "Retornos del amor ante las antiguas deidades", y asimismo en los de "Retornos del amor fugitivo en los montes", y "Retornos del amor entre las ruinas ilustres". En el primero se revive la identificación de la amada con las diosas. En el segundo se evocan los días de amor, no sin sombras acechantes, en Ibiza, espacios que se recuerdan "como una isla de Teócrito". En el tercero unas ruinas, probablemente del mundo romano, estimulan la remembranza de amorosos ardores pretéritos.

\section{De mar a mar}

Tras esta apretadísima revista panorámica de la presencia de la mitología en las obras que preceden a Ora marítima, vamos a centrarnos ya, y exclusivamente, en este conjunto de 1953 que fue compuesto para conmemorar el tercer milenario de la fundación de Cádiz, y en el que se recrean los orígenes legendarios gaditanos. La salida de este libro, en el otoño de dicho año, fue paralela a la muestra de textos poéticos y de pinturas de Alberti celebrada en Buenos Aires, en la Sala Rial, bajo el título de "Homenaje lírico plástico al trimilenario de la fundación de Cádiz”.

No cabe duda que Retornos de lo vivo lejano, al igual que Ora marítima, fueron concebidos como conjuntos originados desde los recuerdos, y en su virtud se acostumbra a juntarlos dentro de unas mismas coordenadas, en las cuales también cabe, ciertamente, A la pintu$r a$. Empero, en Retornos... se contendría el germen de ese triple y común impulso lírico susceptible de englobar a los citados libros, conforme ha advertido la crítica más competente: "Ora marítima es un esqueje muy particular de ese libro inagotable (venero de poemas y poemas, de vivencias y vivencias) que es Retornos de lo vivo lejano. No es casual, sino lógico, que ambos poemarios solapen sus escrituras 
en el tiempo, como que coincida con ellos A la pintura. En los tres (y en muchos momentos de otros libros próximos) se hace un catárquico ejercicio de revivir lo vivido, para no olvidar, para rehuir la rabia, casi la desesperación de haber perdido lo amado, y no recuperarlo a manos llenas". (Torres Nebrera 1999, 93).

Entre otras, tiene Ora marítima una especificidad, empero, en el seno de esta tríada de rememoraciones convergentes, la que le confiere el canto transoceánico del poeta a la idiosincrasia genuina de su tierra, canto creado desde un escenario tan lejano como emparentable con las latitudes de la región gaditana, y es que Alberti compone en esta obra "una elegía a la ciudad del sur desde su presente situación en otro mar del sur y en otra bahía, la de El Plata". (González Martín 1978, 149).

\section{La citación erudita}

Ora marítima es “...el libro más culto, desde el aspecto referencial, de toda la producción de Rafael Alberti” (Ripoll, 1990, 315), y por ende nos sumerge en el mundo antiguo como ningún otro libro suyo, y desde el título mismo, el cual reproduce el que antepuso Rufo Festo Avieno, que vivió en el siglo IV de nuestra Era, al poema en el que fue describiendo en verso latino las costas mediterráneas desde la zona de Tartessos hasta la del Ponto Euxino. De este texto, al parecer compuesto en torno al 350, se conservan 713 trimembres yámbicos de su primer libro.

Además de la deuda del título-cita, Rafael Alberti escogió dos pasajes de aquel escritor geográfico para colocarlos precisamente al inicio $^{2}$ y al término de su conjunto. En el hecho de haber situado ese par de fragmentos en lugares tan significativos como los de apertura y cierre creemos que se enfatiza tanto su voluntad estructuradora como su reconocimiento al autor de Balsena al que debía la titulación bajo la que se reúnen los doce textos poéticos conmemorativos.

Con todo, en Ora marítima no es Avieno la autoridad a la que más se acude, pues la que proporciona más citas, y por ende más asuntos inspiradores, fue el geógrafo e historiador griego Estrabón, cuya existencia discurrió entre los años 63 a.C. y 19 de la Era Cristiana. De este autor oriundo de Capadocia se aducen media docena de

${ }^{2}$ Decir "al inicio" no supone en este caso que la cita anteceda al primer poema del libro, pues está antepuesta al segundo, el cual sí constituye, sin embargo, el verdadero comienzo significativo de la obra, pues el texto uno, "Por encima del mar, desde la orilla americana del Atlántico", desempeña funciones prologales. 


\section{J. $M^{a}$ Balcells}

citaciones, lo que guarda correspondencia con el hecho de que uno de los 17 libros de su Geografía, en concreto el III, está dedicado por entero a la península ibérica, y en él se habla de la región sudoccidental de la misma y de las ciudades allí fundadas, entre ellas la que llama Gádeira, es decir Cádiz.

De otros cuatro autores helenos se reproducen citaciones en este conjunto de Alberti, en el cual se aportan dos fragmentos del filósofo Platón, procedentes de su obra inconclusa Critias o la Atlántida. Ese par de lugares textuales corresponden a los párrafos 114 y 121 de ese diálogo platónico. Son igualmente dos las citas del poeta Hesíodo, sacadas ambas de su Teogonía, mientras de Homero y Estesícoro se utilizan sendos pasajes. El lugar homérico copiado figura en el canto II de la Ilíada. Remiten al canto a Geryón los versos del poeta coral Estesícoro, que falleció en Sicilia el 555 a. C., habiendo nacido en Matauro hacia el 635.

Además de Avieno, en Ora marítima las letras latinas comparecen por medio de dos grandes literatos hispanorromanos: Lucio Anneo Séneca y Marco Valerio Marcial. Del moralista y trágico de Córdoba se traslada un breve parlamento puesto en boca de Hércules, y tomado de la tragedia Hércules furioso, de la cual se reproduce, en español, el texto latino comprendido entre los versos 927 y 939 . Del bilbilitano se alegan los conocidos versos en los que evoca las lascivas danzas de la bailarina de Gades Telethusa, media docena de líneas métricas que conforman la totalidad del epigrama LXXI del libro VI.

Un par más de citas completan el elenco de discursos reproducidos en la obra. Una tiene por autor atribuido, y seguramente incierto, a Jonás, uno de los doce poetas menores veterotestamentarios. Del libro que lleva el nombre de este profeta bíblico se aduce un texto con referencias a Tarsis. La otra es del Kitab al-Rawd al-Mitar, del primero de los califas almohades, Abd Al-Mun'im Al Himyari, conquistador de Cádiz, entre otras grandes ciudades de Al-Andalus.

\section{Décimo trabajo de Heracles}

Determinada ya la relación de 'autoridades' de que se valió Rafael Alberti en Ora marítima, adelantemos que este libro no se limita a intercalar una gama de referencias míticas, sino que en su decurso se vale el poeta de la mitología como formante sustancial y estructurador de la obra entera. ${ }^{3} \mathrm{Y}$ anotaremos también que varios de los fragmentos

${ }^{3}$ A esta cuestión dedica B. Ophey las páginas 110-23 de su monografía Rafael Alberti als Dichter des verlorenen Paradieses, publicada en Frankfurt/M en 1972. 
respectivos de tales autoridades contienen alusiones mitológicas, siendo Heracles la divinidad más reiterada, seguida del gigante Geryón.

A quien conozca el historial de las hazañas de Heracles no le va a sorprender que sea el personaje mítico con más incidencia en Ora marítima, puesto que tres de sus proezas se relacionan con el orbe hispánico, ocurriendo la primera de ellas en la zona gaditana. Sería ésta la décima de sus gestas, en la que logró la captura de los toros de Geryón, uno de los tres vástagos de Crisaor, rey de Iberia. La oncena y doceava iban a ser, respectivamente, el robo, en el Jardín de las Hespérides, de las áureas manzanas, y el viaje a los infiernos.

El trabajo que hace once de los que acometió Heracles no pretexta ningún texto albertiano, no obstante lo cual no se resiste el poeta en apostar por Cádiz como la zona donde moraban las Hespérides, es decir las hijas de la Noche. Así se colige de un par de versos de la estrofa sexta del poema "Cádiz, sueño de mi infancia", en donde leemos: " $¡$ oh gaditano mar de los perdidos / Atlantes, vesperales jardines de la espuma".

Respecto a la doceava de las empresas de Heracles, la del viaje al Hades, tampoco sirve en Ora marítima como excusa inspiradora de una composición determinada. Sin embargo, del mismo modo que habría situado el hespérico jardín en el área de Cádiz, según el poema "Riotinto, lago del infierno", el Tártaro se enclavaría igualmente en ese territorio sureño, apoyándose para esta hipótesis en la cita de Estrabón que va al frente de ese texto, y que dice como sigue: “...Pero como la noche, por su nombre siniestro, evoca evidentemente la idea de un lugar próximo al Hades, y éste a su vez confina con el Tártaros, pudo creerse que Homero se sirvió de lo que había oído a Tartesos, asimilando este nombre al de Tártaros, para aplicarlo luego a la parte más alejada de las regiones subterráneas..."

Luego, en la lectura de los versos de "Riotinto, lago del infierno", no vamos a encontrarnos mención alguna a ese trabajo último de Heracles, pero sí unos pocos elementos que tienen distinta relación con él, como son las Gorgonas, una de las cuales tuvo un enfrentamiento con el héroe ante una de las puertas del Hades. Además, Rafael Alberti daba principio a dicho poema con unos octosílabos asociables a las simas plutónicas:

${ }^{4}$ Cf. Rafael Alberti. Obra Completa. Poesía 1939-1963. Edición de Luis García Montero, Madrid (Aguilar) 1988, II, 649. (Todas las citas de versos de Alberti se harán por esta edición, a la que se hará referencia breviadamente: $O C . P$ ). 
J. $M^{a}$ Balcells

\begin{abstract}
Me traen los vientos ráfagas
del palacio de la Noche.

A infierno huele la mar,

las olas levantan fuego.

En las murallas de Cádiz

se despedazan en fuego 5 .
\end{abstract}

Y ahora, por su alta incidencia en Ora marítima, no estará de más que recordemos sucintamente el argumento de la décima empresa de Heracles, pero no sin llamar previamente la atención acerca de que Rafael Alberti no problematiza, y tampoco hubiera resultado sitio idóneo para ello, la identidad y procedencia genealógica del héroe al que se conoce con ese nombre. En su libro no interesa al poeta especular sobre los Heracles egipcio y tebano, sino que se refiere expresamente al hijo de Alcmena, el cual, como nos informa la mitología griega, tuvo por padre a Zeus y por abuelo a Perseo. Pero no demoremos ya más el resumen del trabajo que hizo diez en la cuenta del héroe.

Una vez culminado con éxito un noveno trabajo, el monarca micénico Euristeo encomendó a Heracles un décimo reto, el ya mencionado del robo de los cornúpetas pertenecientes a Geryón. No sólo su colosalidad distinguía a este gigante, sino otros elementos físicos excepcionales, pues sus cabezas eran tres, al igual que sus troncos, y seis eran sus brazos, lo mismo que sus piernas. Si su figura infundía pavor, enfrentarse a él implicaba una proeza extrema, puesto que sus dos hermanos, también gigantes, siempre combatían a su lado, comandando un ejército numeroso. Enfrentado a unos oponentes de tanta envergadura, Euristeo tenía la convicción de que Heracles, cuya fama envidiaba, no iba a superar tamaños obstáculos, y perecería. Sin embargo, salió airoso de este décimo trance.

Como primera decisión con vistas al cumplimiento del mandato, congregó Heracles a todas sus tropas en la isla de Creta. Allí lucha contra el gigante Anteo, hijo de la diosa Gea, la Tierra. Dado que Anteo recuperaba todas sus fuerzas al tocar la tierra, el héroe hubo de matarlo estrechándolo fuertemente entre sus brazos y manteniéndolo en vilo, sin aquel contacto reparador, y acabando con él por vía de estrangulamiento. Sucedió a esta victoria un dilatado peregrinaje, en el transcurso del cual funda la ciudad de Hecantopulos. El punto último de su periplo era el Atlántico, y a sus costas arribó, por el meridión de Iberia, allá en la bahía gaditana.

\footnotetext{
${ }^{5}$ OC.P. 653-654.
} 
En Cádiz, Heracles erige las columnas que llevan su nombre. La península entera cae bajo su dominio cuando derrota a los hijos de Crisaor y a sus ejércitos. Luego se traslada a la isla de Eritea, en la que guardaba Geryón la manada de astados. Nada más puso el pie en suelo insular, le saldría al paso un perro bicéfalo y también un pastor, pereciendo ambos a causa de los golpes de su maza. Apoderado de las reses, se escapó con ellas, pero Geryón le persigue, le da alcance y se entabla una lucha implacable entre los dos.

El combate fue terrible, interfiriendo en él la diosa Hera a favor de Geryón, pues era enemiga declarada de Heracles. Como explicación de este comportamiento contra el héroe, no se olvide que esta divinidad mitológica griega fue no sólo hermana, sino esposa de Zeus, quien la habría engañado con Alcmene, madre de Heracles, de ahí que Hera hubiese resuelto vengarse contra su rival en la persona de su hijo. Tras esta aclaración, recuperamos el hilo de la leyenda para contar que Heracles disparó una flecha contra la deidad femenina, logrando herirla en el pecho y ocasionando su huida. El gigante caería después abatido por medio de otra flecha que se le clavó en el estómago, en el que se unían sus tres troncos. Acabada esta gesta, abandonó Iberia rumbo a la península itálica.

Si se repasa la trama descrita, se observa que, en ese décimo episodio de las legendarias proezas de Heracles, el viaje mítico constituye un pretexto sine qua non. Euristeo, en efecto, le ordena ir a Iberia, y a ese lugar va a encaminarse desde suelo cretense, y atravesando muchas regiones. Ya situado en el Atlántico gaditano, la guerra contra los vástagos de Crisaor le hará desplazarse por la península, y más tarde navegar hasta la isla Eritea, donde finaliza la empresa de apoderarse de los toros.

En el segundo de los poemas de Ora marítima, titulado "Cádiz, sueño de mi infancia", Rafael Alberti se hace eco de la constante situación viajera de Heracles, al que califica como "vástago errabundo". En la primera estrofa alude a su venida al Atlántico, y al robo de los morlacos de Geryón, un nombre que, según la cita de Avieno que el poeta puso al frente de este texto, una cita que en realidad resulta de un conglomerado de tres, ${ }^{6}$ derivaría de la fortaleza llamada Geronte, nombre a su vez procedente de la palabra Grecia. Pero traslademos la estrofa antecitada:

Te miraba de lejos, sin comprenderme, oh Cádiz,

\footnotetext{
${ }^{6}$ Integran esta cita, en efecto, los versos 85-86; 261-265; y 390-393.
} 
a orillas de tu mar, por la que el férreo Alcides, el vástago errabundo, hijo feliz de Alcmena, después de abrir las puertas azules del Océano, pasó a robar los toros bravos de las marismas en donde Geryón, pastor y rey,

de tres grandes cabezas ornado, gobernaba ${ }^{7}$.

$\mathrm{El}$ "Te miraba de lejos..." con el que empieza la estrofa rememora la época en la que el poeta divisaba, de niño, la ciudad de Cádiz en la lejanía, y desde su localidad natal. Ahí, en el colegio San Luis Gonzaga, supo de la fundación de Cádiz y supo de los hechos gaditanos de Heracles, acontecimientos ambos sobrevenidos merced a viajes marítimos:

Te miraba, distante, desde un libro de texto, a través de las palmas datileras, los nísperos, las finas transparentes araucarias del jardín colegial en donde un día supe de las fenicias naves y las Columnas que tú, naciente Gádir, consagrabas al héroe ${ }^{8}$.

La somera referencia a la fundación de Cádiz por los fenicios va a ser asunto nuclear, como veremos, de otro poema de este libro, de título declarativo donde los haya: "Los fenicios de Tiro fundan Cádiz". Conocido este hecho por Alberti en sus días colegiales, y por un libro de texto, en Baladas y canciones del Paraná se incluye una canción en la que se plasma cómo el poeta, a través de las lecciones escolares cursadas por su hija Aitana en Argentina, se reencontró con ese dato histórico al cabo de muchos años. Estamos aludiendo al texto "Se fue ya Aitana. (Corre el tren,", del que copiamos estas dos redondillas eneasilábicas:

A los fenicios los llamaron los carreteros de la mar.

Comerciar, sólo comerciar era el oficio que inventaron.

Llegaron a Cádiz un día,

\footnotetext{
${ }^{7}$ En OC.P., 648.

${ }^{8}$ OC.P., ibídem.
} 
El viaje mítico en Ora maritima, de $R$.

después de pasar Gibraltar.

Hércules, que los vio llegar,

les concedió la factoría?

El robo de los toros por Heracles se menciona también, como hemos comprobado, en el poema "Cádiz, sueño de mi infancia", donde no se desarrolla poéticamente ese suceso, el cual se va a desplegar en el texto siguiente, "Bahía de los mitos", al que preceden dos citaciones eruditas. En la de Estesícoro leemos que Geryón nació "junto a las fuentes inmensas de Tartesos". En la de Hesíodo se establece la genealogía de Geryón y se refiere el lance de cómo se apoderó el héroe de las reses. Reproducimos las líneas concretas de la Teogonía: "Crisaor engendró a Geryón, el de las tres cabezas, unido a Callirroe, hija del ilustre Océano. A aquél, Heracles el Fuerte lo mató, junto a sus toros de torcidos pasos, en Erytheia, que circundan las olas, el día que él arreó sus toros de anchas frentes hacia la santa Tyrinto, después de haber franqueado la corriente del Océano y haber matado juntamente a Orthos y Eurytión el boyero, en su dehesa brumosa, más allá del ilustre Océano" ${ }^{\prime \prime}$.

Principia después el poema "Bahía de los mitos" imaginándose el poeta "...sentado en la arena,/ playa azul de mi bahía". Al llegarle al hablante, por el aire, bramidos de cornúpetas desde las marismas, los asocia a los toros "acosados" de la leyenda, asociación que le da pie para plasmar el evento del robo a partir de la estrofa cuarta, y hasta la séptima y última, estrofas que transcribimos:

¿Qué fuerza sagrada arranca

las rocas de la bahía?

Lamentos de can herido,

de dios ya casi sin vida.

Geryón, rey de Tartesos,

rey fluvial, dios de la Isla

del Ocaso, y mayoral

de toros en las marismas.

Mayoral de toros bravos

de las marismas.

Mazazos de clava tunden

\footnotetext{
${ }^{9}$ OC.P., 746.

${ }^{10}$ Estas líneas son traslado de los versos 287-294 de la Teogonía.
} 
J. $M^{a}$ Balcells

los ecos de la bahía.

Las tres cabezas del rey

mugiente ruedan partidas.

Las dos cabezas de Orthos,

su perro, también partidas.

Y Eurityón, pastor del rey, boyero de las marismas, vuelca, partido, su sangre, por las marismas.

Gritos de Heracles el Fuerte retumban en la bahía.

¡Eh, que se llevan los toros, los bravos toros de lidia!

Torbellinos de testuces y de cuernos que se astillan. Mugir del mar y del viento de las marismas.

-Abriendo un nuevo camino, los litorales arriba, va Heracles, ladrón de toros de las marismas ${ }^{11}$.

\section{Los regeneradores Atlantes}

El poema insertado a continuación de "Bahía de los mitos" es "La Atlántida gaditana", y entre su título y el texto albertiano se han copiado dos pasajes platónicos del Critias, el segundo de los cuales inspira, como se verá, el meollo de la composición, en cuyos versos el asunto del viaje se enfoca de un modo sui generis. Y es que dos clases de travesías se evidencian aquí, una desde la actualidad hasta un lejano pretérito mítico, y una segunda desde ese pasado remoto hasta el presente. Otro rasgo peculiar revisten asimismo ambas singladuras, la de producirse respectivamente de arriba hasta abajo, y desde abajo hasta arriba, siempre a través del mar, con lo que las palabras clave de los dos trayectos son "sumergirse" y "emerger".

Los vocablos antecitados actúan en un doble plano, el marítimo y el cronológico, y así el sumergimiento será en el océano y en el tiempo, y el emerger será desde el fondo y hasta la superficie, cruzando los

${ }^{11}$ OC.P., 650-651. 
siglos. El periplo de ida en pos del mundo antiguo lo protagoniza el yo poemático. El de aproximación al hoy es reclamado por éste a la etnia de los Atlantes, habitadora de una primitiva tierra sepultada bajo las aguas, a tenor del especulativo postulado platónico. Ese par de viajes comprenden aún más singularidades: el segundo será consecuencia del anterior, porque es el poeta quien metafóricamente se sumerge, desde el litoral americano, hundiéndose en las profundidades oceánicas gaditanas para apelar al supuesto pueblo desaparecido a que se alce desde las simas marinas, y comparezca y regenere el actual orden de cosas humano. Así se dice en la segunda y tercera estrofas:

Lejos, sentado ahora en las contrarias orillas, recibiendo las mismas oceánicas olas, me voy con ellas, llego con ellas y mis ojos hundo, todo yo me sumerjo en tan antiguo sol misterioso, isleña raza potente desaparecida.

Álzate, surge, sube, asciende de los hondos despeñaderos submarinos. Véate pura y viril poblar la nueva tierra.

Renovadas se ostenten tus remotas virtudes. Hombros inexpugnables, corazones incorruptibles, manos inmáculas emerjan. Corra tu ardor por la cansada sangre ${ }^{12}$.

El imperativo regenerador para el que los Atlantes son convocados se expresa en la estrofa cuarta, en la que no se denuncia la situación política de un país concreto. No obstante, en los versos del poeta se alude a gentes humilladas y sometidas, a hombres carentes de libertad, situaciones que, en cualquier caso, afectaban al pueblo español bajo el franquismo coetáneo, y asimismo a quienes viviesen bajo otras dictaduras. Léanse los primeros seis endecasílabos de la estrofa:

Pechos doblados sufren hoy el mundo, prestos a henchirse de tan limpios hálitos. Puedan los hombres respirar tranquilos, mirar al cielo sin beber la muerte.

\footnotetext{
${ }^{12}$ OC.P, 652-653.
} 
Ancha morada, límites sin llaves, de par en par se extiendan para todos ${ }^{13}$.

\section{Fundación fenicia de Cádiz}

Anotábamos antes que en el poema "Cádiz, sueño de mi infancia", la segunda de las estrofas alude a la fundación de la Ciudad, debida a los fenicios, allá por el año 1100 a. C, según consigna el propio Alberti en la dedicatoria de Ora marítima y según escribió él mismo en el catálogo de la exposición bonaerense de poemas y de pinturas a la que nos referíamos más arriba, y donde se lee: "La ciudad más antigua de Occidente -Gádir para los fenicios, Gádeira para los griegos, Gades para los romanos, Cádiz, en fin, para árabes y españoles- celebra en el curso de este 1953 los tres mil años de su fundación. Naves fenicias de Tiro arribaron a sus arenas, abriéndole los ojos a la luz del Atlántico en el año 1100 antes de J.C., consagrándola a la divinidad más popular y heroica de las azules mitologías mediterráneas: a Melkart, el Heracles helénico, el Hércules latino"14.

Cádiz habría tenido origen en la tercera de las expediciones de los tirios, de acuerdo con la cita de Estrabón que va al frente del texto albertiano titulado "Los fenicios de Tiro fundan Cádiz". He aquí el pasaje del geógrafo griego: “...dicen recordar los gaditanos que cierto oráculo mandó a los tirios fundar un establecimiento en las Columnas de Heracles. Los enviados para hacer la expedición llegaron hasta el estrecho de Calpe, y creyeron que los promontorios que forman el estrecho eran los confines de la tierra habitada, y el término de las empresas de Heracles. Suponiendo entonces que allí estaban las Columnas de que había hablado el oráculo, echaron el ancla en cierto lugar de más acá de las Columnas, allí donde hoy se levanta la ciudad de los exitanos. Mas como las víctimas no fueron propicias, entonces se volvieron. Tiempo después, los enviados atravesaron el estrecho, llegando hasta una isla consagrada a Hércules, situada junto a Onuba, ciudad de Iberia y a unos mil quinientos estadios fuera del estrecho. Como creyeron que estaban allí las Columnas, sacrificaron de nuevo a los dioses. Mas otra vez fueron adversas las víctimas, y regresaron a su ${ }^{13}$ Idem, 653.
Solo la mar. Antología al cuidado de María Asunción Mateo, Madrid (Espasa-Calpe) 1994, p.122. 
patria. En la tercera expedición fundaron Gádeira, y alzaron el santuario en la parte oriental de la isla, y la ciudad en la occidental". ${ }^{15}$

Pese a estar presidido por la cita de Estrabón, el poema se apoyará en referencias bíblicas al cantar los orígenes y el ajetreado tráfico naviero y comercial de la zona que fue llamada Tarsis, y cuyo emplazamiento es un misterio. Con todo, mayoritariamente se coincide en admitir que estaba situada al oeste del peñón gibraltareño, y que su capital era Tartesos. Varios profetas veterotestamentarios (Ezequiel, Isaías, Jeremías) dejaron constancia de los viajes de los fenicios a la costa oeste de la actual Andalucía, y Rafael Alberti los incorpora a su texto, dándoles voz.

El poema "Los fenicios de Tiro fundan Cádiz" está emplazado en el centro del libro, en ubicación probablemente deliberada para acentuar su relevancia significativa en una obra que toma como pretexto la fundación de esa ciudad. Versos de carácter apologético, la apología de la urbe da comienzo ya en las dos líneas primeras de la composición, en las que se compara el nacimiento de Cádiz al de Afrodita, una diosa de hermosura suprema y de enorme influencia sobre los hombres y sobre los dioses. Comparanza, así pues, adecuada para ensalzar tanto la belleza como la importancia histórica de la ciudad que, con el nombre de Gades, sucedió a Tartesos, quizá destruida por los cartagineses, como capital de Tarsis. Escribe el poeta:

$$
\begin{aligned}
& \text {...Y así naciste, oh Cádiz, } \\
& \text { blanca Afrodita en medio de las olas. } \\
& \text { Levantadas las nieblas del Océano, } \\
& \text { pudiste en sus espejos contemplarte } \\
& \text { como la más hermosa joven aparecida } \\
& \text { entre la mar y el cielo de Occidente }^{16} \text {. }
\end{aligned}
$$

\section{El Cádiz inalcanzable de Jonás.}

En el poema siguiente, la anécdota la protagoniza un profeta bíblico distinto a los que hablan en el anterior, tal como se declara en el título "Huida del profeta Jonás a Tartesos". En el texto se poetiza el intento de Jonás de viajar al litoral de Cádiz, tratando de huir de Jehová tras desobedecer su mandato de que fuese a predicar a Nínive. Rafael Alberti imagina en el poema que eran marineros gaditanos quienes iban a trasportar al huido en barco, hasta Tarsis. Así se lo asegura

\footnotetext{
${ }_{15}^{15}$ Cita tomada de la Geografía, Libro V, Parte quinta, párrafo 5.

${ }^{16}$ OC.P., 655.
} 
quien comanda la nave y asimismo uno de los remeros, no sin alentarle con la protección de Heracles y no sin que sean mencionadas las inolvidables danzarinas de la zona.

Sin embargo, Jonás no pudo coronar el viaje emprendido, puesto que otro bien distinto y extraordinario le aguardaba. Y es que, como sabemos por la literatura bíblica, una fuerte tempestad se cebó con la embarcación y los marineros intentaron salvarse del naufragio desprendiéndose de la carga que consideraban prescindible. A la vez, trataron de averiguar, echándolo a suertes, quién de los presentes había encolerizado a los dioses como para que desencadenasen la tormenta. Como la fortuna señaló al fugitivo, lo arrojaron por la borda, con lo que amainó la furia del mar.

La fantasía reemplaza desde aquí a la verosimilitud en el relato bíblico, en el que se cuenta que una ballena se tragó a Jonás, permaneciendo en su vientre por espacio de tres días y tres noches. A continuación fue vomitado en una playa por el cetáceo, y sin haber sufrido daño alguno. Leamos, reproduciendo la segunda mitad del poema, el enfoque albertiano de esta historia fantástica de un libro tan escueto como novelesco ${ }^{17}$ :

Y dijo el patrón del barco

a Jonás:

-Vendrás a Cádiz primero.

Vendrás.

Heracles es fuerte. Heracles

es más fuerte que Jehová.

Y hubo un remero del barco

que también dijo a Jonás:

-Vendrás a Cádiz primero.

Vendrás.

Las bailarinas de Cádiz...

No dijo más.

No pudo decir ya más.

Una ballena del fondo

\footnotetext{
${ }^{17}$ Así califica Isaac Asimov a este libro en su utilísima Guía de la Biblia, Barcelona (Laia) 1985, P.590.
} 
El viaje mítico en Ora maritima, de $R$.

subió y se tragó a Jonás ${ }^{18}$.

\section{Menesteo y El Puerto}

El motivo del viaje reaparece en Ora marítima tres textos después de "Huida del profeta Jonás a Tartesos", en concreto en la composición titulada "Menesteo, fundador y adivino", que es el único poema del libro al que preceden tres citas, una de la Ilíada y dos de la Geografía de Estrabón. En el fragmento seleccionado de la epopeya homérica se hace referencia al caudillo ateniense Menesteo, gran guerrero y navegante, al que "Cincuenta negras naves le seguían". En la primera de las de Estrabón se mencionan como históricas las andanzas de este héroe, y en la segunda se nombra "el puerto llamado de Menesteo" al ir describiendo el geógrafo el litoral gaditano. Y en este punto puntualiza el poeta que ese lugar se corresponde con su ciudad natal, El Puerto de Santa María.

No fue Menesteo, ciertamente, uno de los héroes máximos en la contienda troyana, pero sí fue un guerrero y navegante de singulares méritos, asociándose a su vida la circunstancia de haberse desplazado, por mar, hasta las costas gaditanas, donde fundó el puerto de su nombre, siglos más tarde renombrado con la onomástica mariana con que hoy se le conoce. Los versos dedicados por Alberti al fundador de su villa nativa son celebrativos, y parten, al igual que "Cádiz, sueño de mi infancia", de la remembranza de cuándo empezó el poeta, en su niñez gaditana, a tener noticias de Menesteo:

Supe de ti, primero, magnánimo ateniense, héroe y divinidad ante los muros sacrosantos de Troya, frente a la mar de Cádiz, en las mismas arenas y al pie del mismo río adonde tú, tal vez patrono y marinero de las naves de Ulises, llegaste una mañana. Supe de ti, primero, en esas noches en que los maternales arrullos van poblando el tardo sueño niño de pórticos azules ${ }^{19}$.

En una segunda estrofa salen a relucir, de nuevo, las columnas de Heracles y los toros tartésicos, retornando en la tercera el motivo del

\footnotetext{
${ }^{18}$ OC.P., 658.

${ }^{19}$ Ídem, 662.
} 
viaje: "Jinete de la tierra y de las olas,/ me trajiste los carros de la Ilía$d a, /$ llenándome de añiles y cal mediterráneos".

Desde la estrofa cuarta clama el hablante por un regreso de Menesteo, a través de los siglos, a la actualidad contemporánea, y para que pueble otra vez de mitos la bahía. Como incentivo, le son ofrecidas todas las azoteas de las casas, a fin de que pueda contemplar Cádiz. La composición termina expresando la voluntad de que los naturales de la zona celebren ese retorno:

Celebremos en alto, frente a la mar redonda, con una copa clara llena de mediodía,

tu retorno a las playas y puertos familiares,

los que en una mañana brotamos de tu escudo ${ }^{20}$.

\section{Resurgimiento de Heracles}

La apelación a Menesteo para que, con su regreso en pleno siglo $\mathrm{XX}$, haga revivir el remoto pretérito de la bahía gaditana, conforma un viaje a través del tiempo que se asocia a otros retornos no menos ansiados, así el de Heracles, un retorno que supondría el renacimiento de este mito tras la simbólica pérdida de poder como consecuencia de la demolición de su templo, a mediados del siglo XII.

La dialéctica entre el Heracles abatido y un Heracles que se anhela torne a resurgir se poetiza en las dos composiciones finales del libro, respectivamente tituladas "Destrucción del templo gaditano de Hércules", y "La fuerza heracleana". La primera está impregnada de tonalidad elegíaca, toda vez que en ella se expresa el simbolismo de la muerte del héroe mítico cuando los árabes, en 1145, arrasaron aquel sacro edificio dedicado a su culto, episodio funesto en la historia de Cádiz, y es que, como se dice en los seis primeros octosílabos del texto,

Todo no iba a ser azul, no iba todo a ser alegre.

El dios de Cádiz un día

halló en el fuego la muerte.

Hércules, el caballero

de la mar, halló la muerte ${ }^{21}$.

\footnotetext{
${ }^{20}$ Ibídem, 653

${ }^{21}$ Ídem, 664.
} 
En el último poema se suceden las manifestaciones de deseo de que la 'fuerza' de Heracles, aquí entendida como poderosa capacidad transformante, se abra paso de nuevo ante el mundo para producir un cambio drástico en el negativo statu quo actual, redimiéndolo de servidumbres.

El viaje de vuelta heracleano alimenta la esperanza en un futuro libre para España y para las tierras de Cádiz, puesto que uno de los principales empeños de ese semidiós fue, como se proclama en la cita del senequiano Hércules furioso que va al frente del texto, "Que no reinen más tiranos crueles y salvajes".

El locutor poemático, por tanto, en el tramo conclusivo de Ora marítima recupera el pasado mítico gaditano en las figuras de Menesteo y de Heracles para proyectar desde ese ámbito un mañana español sin la tenaza de la dictadura franquista, la cual iba a ser debelada, sobre todo, por la reaparición de la severa fortaleza heracleana. Ora marítima concluye con estos versos octosilábicos cuyo contenido se abre a un porvenir optimista:

Columnas esconde el mar

que pueden surgir muy altas.

Heracles, el gaditano,

bajo las olas aguarda ${ }^{22}$.

\section{Bibliografía}

ALBERTI, R.(1953): Ora marítima. Baladas y canciones del Paraná, Buenos Aires (Losada).

ALBERTI, R. (1988): Obra completa. Poesía. 1939-1963. Edición de Luis García Montero, Madrid (Aguilar), vol. II.

ALBERTI, R.(1994): Solo la mar. Antología al cuidado de María Asunción Mateo, Madrid (Espasa-Calpe).

ALBERTI, R. (1999): Retornos de lo vivo lejano, Ora marítima. Edición de Gregorio Torres Negrera, Madrid (Cátedra).

ARGENTE del CASTILLO, C. (1985): "La función del mito clásico en la poesía de Rafael Alberti", en AAVV: Eternidad yacente. Estudios sobre la obra de Rafael Alberti, Granada (Universidad).

GONZÁLEZ MARTÍN, J.P. (1978): Rafael Alberti, Madrid (Júcar).

OPHEY, B. (1972): Rafael Alberti als Dichter des verlorenen Paradieses, Frankfurt/M.

${ }^{22}$ OC.P., 667. 
J. Malcells

RIPOLL, J. R. (1990): “Ora marítima", dentro de AAVV: Rafael Alberti, en el número doble 485-486 de Cuadernos Hispanoamericanos (noviembre-diciembre). 